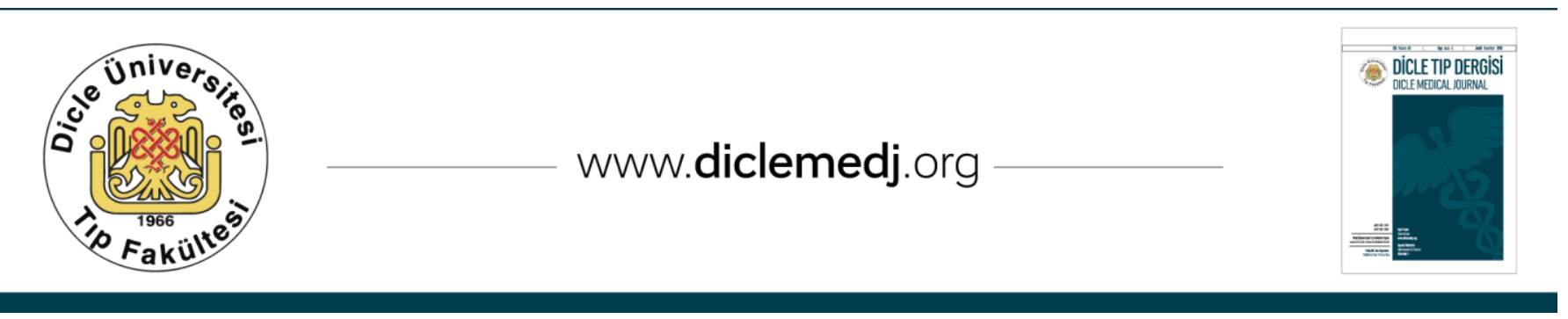

Olgu Sunumu / Case Report

\title{
Sol ana bronş tümörüne sağ torakotomi ile izole sleeve rezeksiyon
}

\author{
Serkan Bayram, Çağatay Tezel, Serdar Evman, Mustafa Akyıl, Volkan Baysungur, İrfan Yalçınkaya \\ Göğüs Cerrahisi Kliniği,Süreyyapaşa Göğüs Hastalıkları ve Göğüs Cerrahisi Eğitim Araștırma Hastanesi, İstanbul, Türkiye
}

Geliş: 28.12.2016; Revizyon: 17.02.2017; Kabul Tarihi: 21.02.2017

\begin{abstract}
Özet
Trakeobronşial sistemin mukoepidermoid karsinomları, submukozal bezlerden gelişen ve primer tedavisi cerrahi olan malign tümörlerdir. Parankim hasarı yapmamış ve bronş dışına yayılımı yok ise izole parankim koruyucu rezeksiyon yapılabilir. Hastamız, sol ana bronşta yerleşik karinaya bir cm uzaklıktaki polipoid lezyonundan biyopsi ile düşük dereceli mukoepidermoid karsinom tanısı alan bir olguydu. Radyolojik tetkiklerinde sağ alt lobta da minimal FDG tutulum gösteren parankim nodülü saptanması üzerine hem nodülün değerlendirilmesi, hem de proksimal yerleşimli sol ana bronș tümörü nedeniyle; hastaya sağ torakotomi ile girişim planlandı. Parankim nodülü benign olarak bildirilince, hastaya sol ana bronş izole sleeve rezeksiyonu yapıldı. Nadir uygulanan cerrahi rezeksiyon tekniğin, literatür eşliğinde tartışılması amaçlanmıştır.
\end{abstract}

Anahtar kelimeler: Mukoepidermoid karsinom, izole sleeve, torakotomi

\section{Isolated sleeve resection of left main bronchus tumor through right thoracotomy}

\begin{abstract}
Mucoepidermoid carcinomas of the tracheobronchial system is a malignant tumor arising from submucosal glands, and the primary treatment is surgery. Isolated bronchial sleeve resection can be performed if there is no parenchymal damage and/or no invasion outside of the bronchus. The patient with a polypoid lesion one $\mathrm{cm}$ from the carina in the left main bronchus, whom biopsy was reported as low-grade mucoepidermoid carcinoma underwent positron emition tomography revealing parenchymal nodule at right lower lobe with minimal FDG uptake with no distant organ and lymph node metastasis. To evaluate the nodule and approach the proximally located tumor in left main brochus; right thoracotomy was planned. When parenchymal nodüle reported as benign, isolated bronchial sleeve resection made to left main bronhus. The rare resection technique discussed with a review of the literature.
\end{abstract}

Keywords: Mucoepidermoid carcinomas, isolated sleeve, thoracotomy

DOI: $10.5798 /$ dicletip. 298620

Yazışma Adresi / Correspondence: Serkan Bayram, Göğüs Cerrahisi Kliniği, Süreyyapaşa Göğüs Hastalıkları ve Göğüs Cerrahisi Eğitim Araştırma Hastanesi, Maltepe, İstanbul, Türkiye Email: dr.serkan@hotmail.com 


\section{GíRIŞ}

Trakeobronşial sistemin mukoepidermoid karsinomları, submukozal bezlerden gelișen, yavaş büyüyen ve primer tedavisi cerrahi olan malign tümörlerdir. Trakeobronşial sistemde çok nadir görülürler ve primer akciğer tümörlerinin \% 0,1-0,2'sini oluștururlar [1]. Düşük dereceli tipi \%80'ini oluşturur. Genç hastalarda düşük dereceli tip görülür ve cerrahi ile tam kür sağlanır [2]. Tipik olarak obstrüksiyon bulguları ile karşımıza çıksa da nadiren astım ya da kronik obstrüktif akciğer hastalığı olarak da yanlış tanı alabilir [3]. Cerrahi yaklaşım, tümör yeri ile yakından ilişkilidir. Santral yerleşimli sol ana bronş tümörüne küratif yaklaşımın sağ torakotomi ile olabileceği olgumuzda gösterilmiştir.

\section{OLGU SUNUMU}

31 yaşında kuru öksürük ile hastaneye başvuran, özgeçmişinde özellik olmayan erkek hastanın solunum kapasitesi düşüklüğü nedeniyle ileri tetkik yapılmış. Toraks bilgisayarlı tomografisinde sol ana bronș proksimal kesiminde $12 \mathrm{~mm}$ çaplı yumuşak doku dansitesinde görünüm saptanıp (Şekil 1a,1b) yapılan brokoskopide sol ana bronşta karinaya yaklaşı $1 \mathrm{~cm}$ uzaklıkta polipoid yapılı kanamaya meyilli lezyon tespit edilip biyopsi alınmış. Histopatolojik inceleme sonucu düşük dereceli mukoepidermoid karsinom olarak raporlanmış. Pozitron emisyon tomografisi sonucunda sağ alt lob superior segmentte subplevral yerleşimli $6 \mathrm{~mm}$ çapında parankim nodülü (SUDmax:1,6) ve sol ana bronş proksimali anterior duvardaki $1 \mathrm{~cm}$ çapında intraluminal yumuşak doku lezyonu (SUDmax:3,4) olarak raporlanmış (Şekil 1c). Sağ akciğerdeki nodülü de aynı seansta incelemek ve tümörün karina ile olan ilişkisini daha rahat değerlendirebilmek amacıyla sağ torakotomi ile rezeksiyon kararı alındı. Rijid bronkoskopi ile tümörün makroskobik olarak karinaya invaze olmadı̆̆ tümörün tam yeri tespit edildi. Ardından sağ torakotomi ile önce pulmoner nodüle wedge rezeksiyon uyguland. Histopatolojik inceleme benign olarak raporlandı. Azygos ven diseke edilerek karina ve sol ana bronş askıya alındı (Şekil 2a). Sol ana bronşa karinadan $1 \mathrm{~cm}$ mesafeden kesilip polipoid kitlenin kaynakladığı iki kıkırdak halka çıkartıldı. (Şekil 2b) Bronş cerrahi sınırlarda malignite tespit edilmemesi üzerine $3 / 0$ polipropilen sütür ile uç uca anastamoz yapıldı. Mediastinel ve hiler lenf nodu diseksiyonu yapıldı. Postoperatif komplikasyon gelişmeyen hasta beşinci günde cerrahi şifa ile taburcu edildi. Histopatolojik inceleme sonucu orta derece mukoepidermoid karsinom olarak raporlandl. Hastaya post operatif kemoradyoterapi verilmedi. Hastanın 3. ay kontrolü tamamen normaldi, toraks tomografisi ve bronkoskopisinde karina ve sol ana bronş açısında stenoz izlenmedi (Şekil 3).

\section{TARTIŞMA}

Mukoepidermoid karsinom, submukozal glandlardan gelişen, nadir görülen ve histopatolojik bulgulara göre düşük, orta veya yüksek dereceli olarak sınıflandırılan malign tümörlerdir [2]. Hava yollarındaki en sık yerleşim yerlerii ana bronş, lob ve segment bronşları olup, irritasyona bağlı öksürük ve dispneye neden olurlar. Tanı sıklkla bronkoskopik biyopsi ile konur. Hem yüksek dereceli hem düşük dereceli mukoepidermoid karsinomlar için cerrahi temel tedavi yöntemidir [4].

Düşük dereceli malign tümörlerde günümüzde parankim koruyucu cerrahi önerilmektedir. Sleeve rezeksiyon veya bronkoplastik prosedurlerin standart tedavi olduğu, kısa ve uzun dönem sonuçlarının iyi olduğu bildirilmektedir [5]. Akciğer kanseri, bronşiyal karsinoidler, bronşiyal tümörler, travmatik veya benign bronşiyal darlıklarda, havayolunun travmatik kopmalarında, hamartom, lipom, schwannom ve granuler hücreli myoblastomlarda da parankim koruyucu 
cerrahi önerilmektedir. Ana bronş veya intermedier bronş yerleşimli tümörlerde parankim koruyucu komplet rezeksiyonla tümörü uzaklaştırmak mümkündür. Hatta segmental bronșial sleeve rezeksiyon yapılarak tüm akciğer parankiminin korunduğu olgular da bildirilmiştir [6].

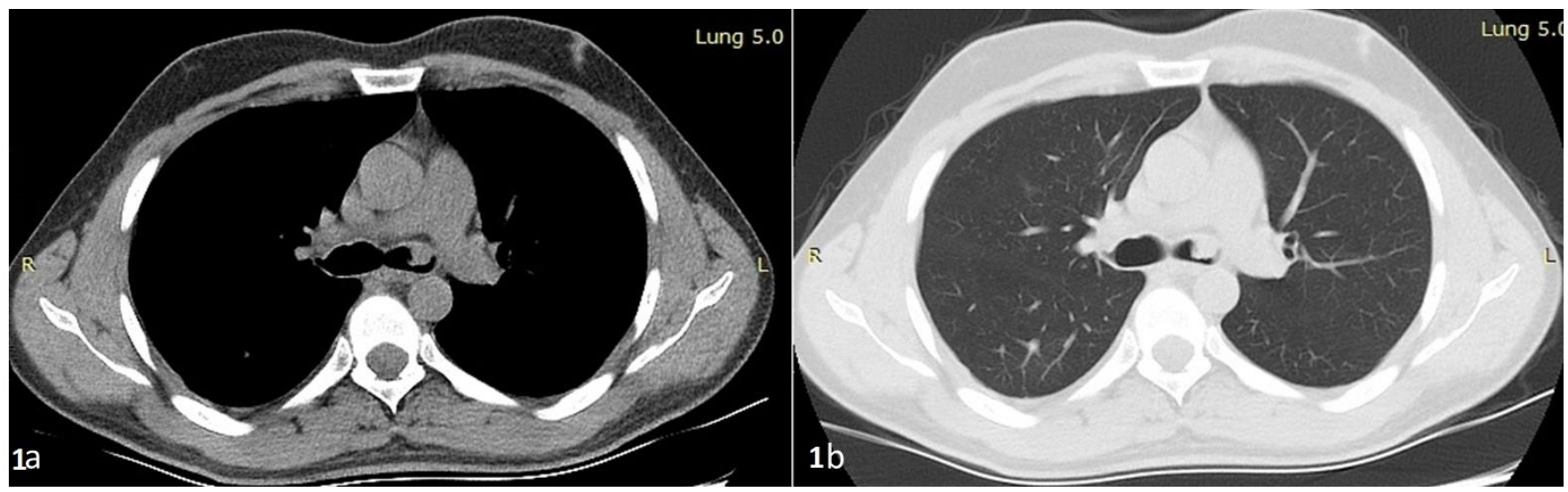

Şekil 1a-1b: Endobronşial yerleşimli tümörün bilgisayarlı tomografi görüntüsü

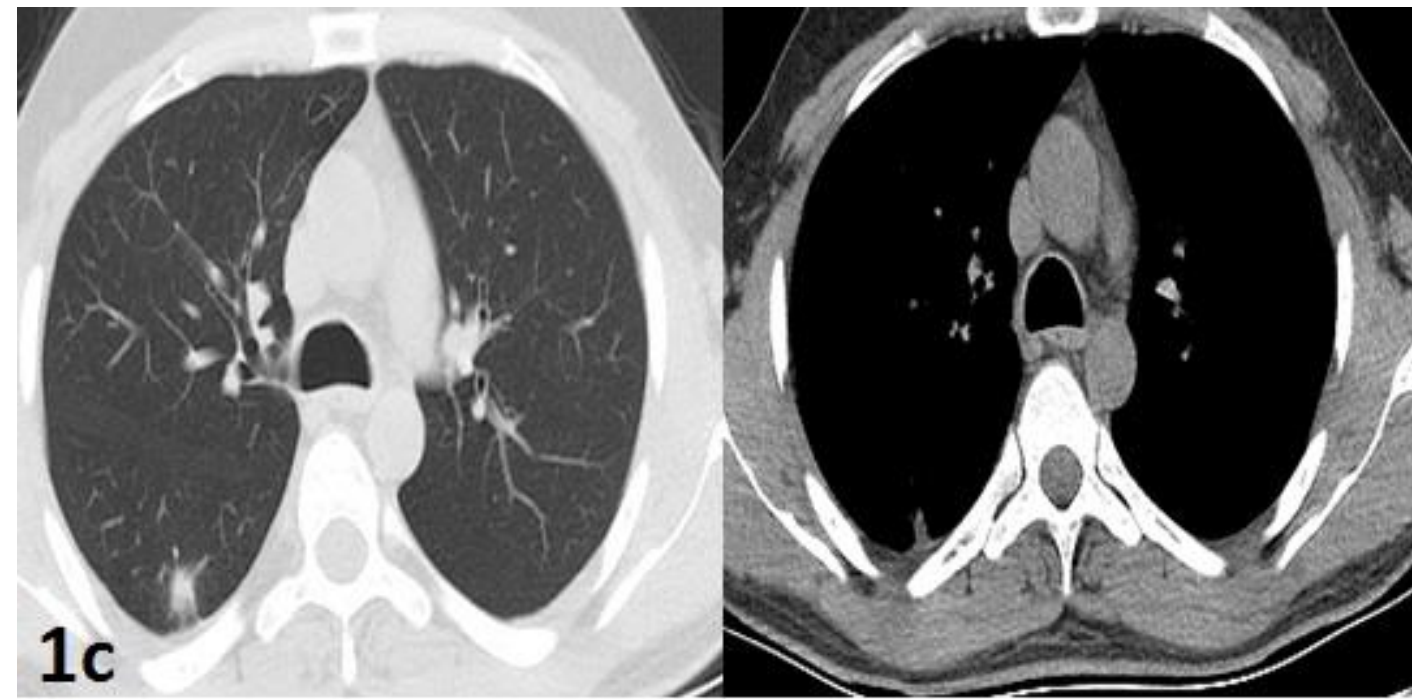

Şekil 1c: Endobronşial yerleşimli tümör ve sağ üst lobtaki parankimal nodülün bilgisayarlı tomografi görüntüsü

Cerrahi yöntem seçimi ise tümörün yerleșimine bağlı olarak değişmektedir. Özellikle sol ana bronş yerleşimi olan ve/veya karina tutulumu da olan hastalarda karinaya erişim için sağ torakotomi önerilmektedir [7]. Median sternotomi de bu hastalarda karinaya daha rahat müdahale imkanı sağlaması ve torakotomiye göre daha az ağrı olması nedeniyle tercih edilebilir [8]. Selektif akciğer ventilasyonunu takiben seçilen teknikle eksplorasyona başlanır ve bronş cerrahi sınır tümörden yeteri kadar uzak olduğu düşünülen hastalarda frozen inceleme sonucu beklenirken anastamoz işlemine başlanabilir.

Histopatolojik olarak temiz cerrahi sınır ve lenf nodu yayılımı olmaması hastalık için kürdür. Sağkalım da lenf nodu yayılımı olup olmamasına bağlı olarak değişmektedir [2]. Düşük dereceli tümörlerde lokal büyüme ile bölgesel lenf nodlarına yayılım \%5'ten azdır. Uzak metastaz nadiren meydana gelir. 
Bayram S., Tezel Ç., Evman S., Akyıl M., Baysungur V., Yalçınkaya I.

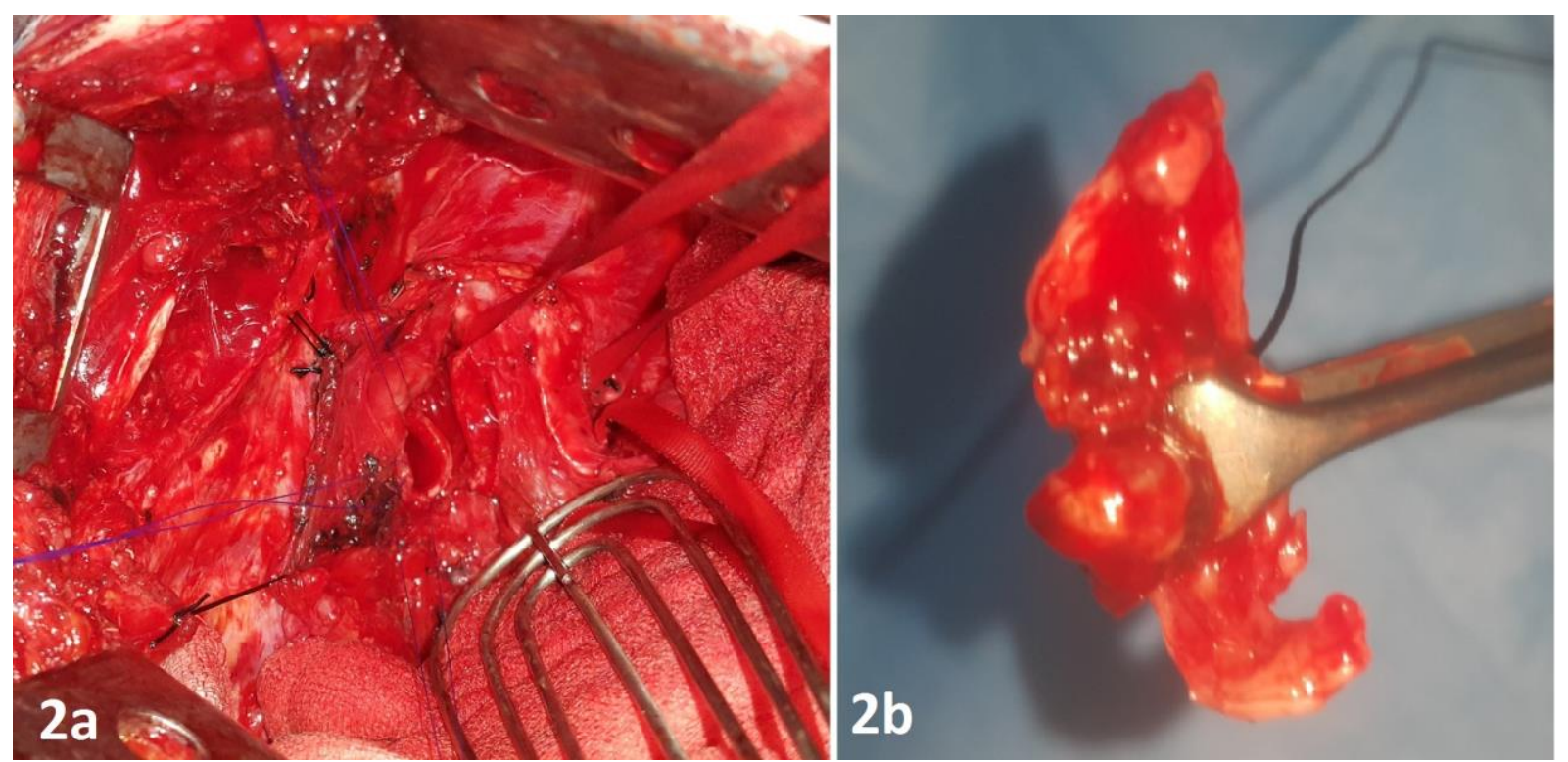

Şekil 2 (a) Sol ana bronșun tümör sleeve rezeksiyonu sonrası intraoperatif görüntüsü, Şekil 2b: Endobronşial tümörün makroskobik görüntüsü

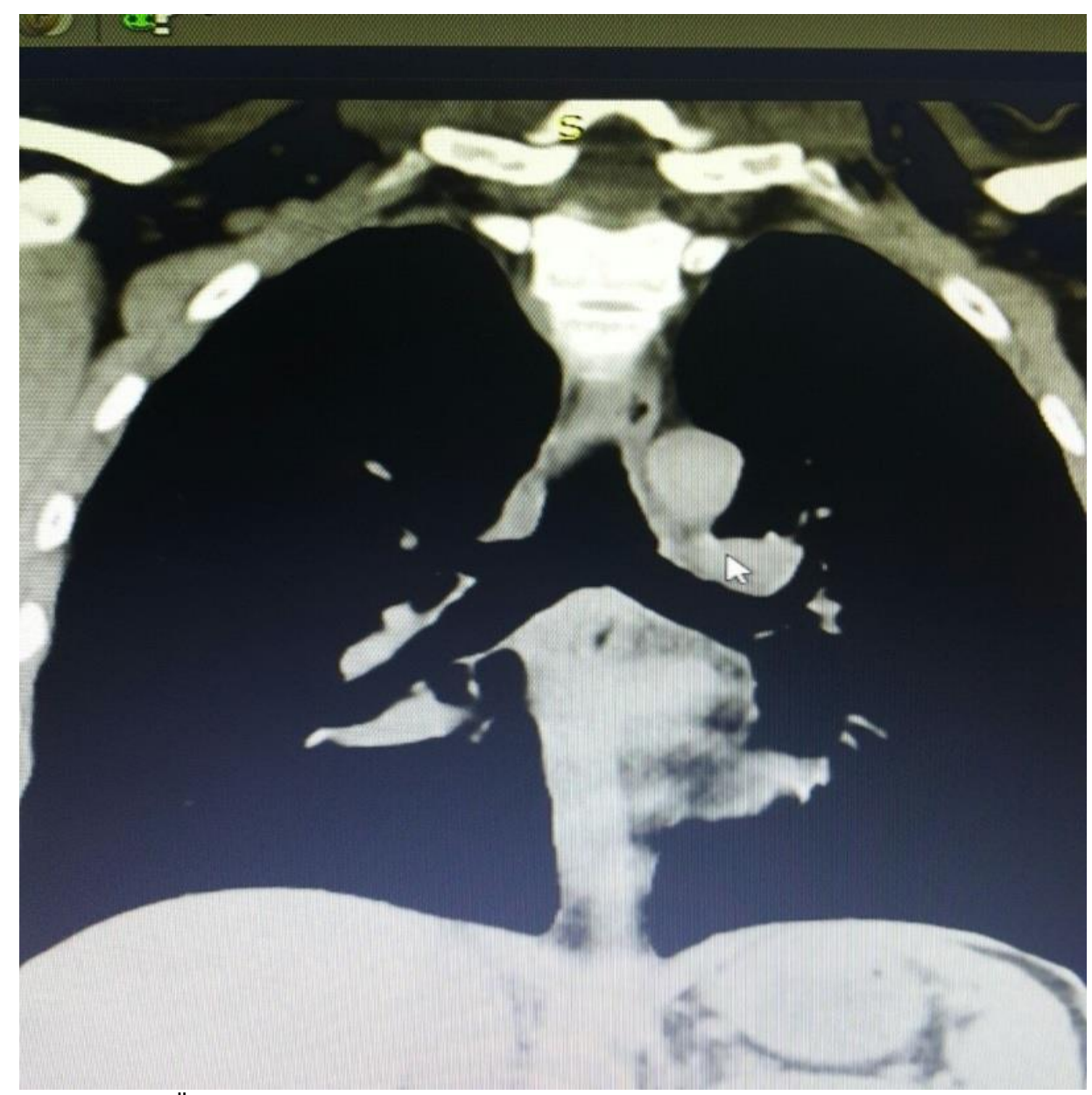

Şekil 3: Üçüncü ay kontrol bilgisayarlı tomografisinde trakea sol ana bronş ilişkisi 
Olgumuzdaki gibi sol ana bronş proksimal yerleşimli tümörlerde izole bronşial sleeve rezeksiyon sağ torakotomi ile rahatlıkla gerçekleştirilebileceği gösterilmiştir. $\mathrm{Bu}$ ve benzeri düşük grade malign tümörlerde bronşial sleeve rezeksiyonlar parankim kaybı olmadığı için hastada fonksiyonel kayba neden olmamakta ve ilk planda tercih edilmelidir.

Çıkar Çatışması Beyanı: Yazarlar çıkar çatışması olmadığını bildirmişlerdir.

Finansal Destek: Bu çalışma her hangi bir fon tarafından desteklenmemiştir.

Declaration of Conflicting Interests: The authors declare that they have no conflict of interest.

Financial Disclosure: No financial support was received.

\section{KAYNAKLAR}

1. Heitmiller RF, Methisen DJ, Ferry JA, et al. Mucoepidermoid lung tumors. Ann Thorac Surg 1989;47:94-9.

2. Vadasz P, Egervary M. Mucoepidermoid bronchial tumors: a review of 34 operated cases. Eur J Cardiothorac Surg 2000;17:566-9.

3. Cicutto LC, Chapman KR, Chamberlain D, Dawney GP. Difficult asthma: consider all of the possibilities. Can Respir 2000;7:415-8.

4. Ishizumi T, Tateishi U, Watanabe SI, et al. 18 FDGPET/CT imaging of the low grade mucoepidermoid carcinoma of the bronchus. Ann Nucl Med 2007;20:299-302.

5. Suen HC, Meyers BF, Guthrie T, et al. Favorable results after sleeve lobectomy or bronchoplasty for bronchial malignancies. Ann Thorac Surg 1999;67:1557-62.

6. Yavuzer S, Yüksel C, Kutlay H. Segmental bronchial sleeve resection: preserving all lung parenchyma for benign/low-grade neoplasms. Ann Thorac Surg. 2010;89:1737-43.

7. Haralabos Parissis, Vincent Young. Carinal surgery: experience of a single center and review of the current literature. J Cardiothorac Surg. 2010;5:51.

8. Maruf Şanlı, Bülent Tunçözgür, Ahmet Feridun Işık, et al. Sleeve resection of mucoepidermoid carcinoma in left main bronchus through median sternotomy. Turk Gogus Kalp Dama 2010;18:151-3. 